EESTI NSV TEADUSTE AKADEEMIA TOIMETISED. 31. KOIDÉ

FOOSIKA * MATEMAATIKA. 1982, NR. 2

ИЗВЕСТИЯ АКАДЕМИИ НАУК ЭСТОНСКОИ ССР. ТОМ 31

ФИЗИКА * МАТЕМАТИКА, 1982, Ni 2

Е. И. САГУН, Г. П. ГУРИНОВНЧ,

А. П. ЛОСЕВ, Э. И. ЗЕНЬКЕВИЧ

удк 535.373 .2

\title{
ФОТОНИКА ХЛОРОФИЛЛА И ЕГО АНАЛОГОВ В КОНЦЕНТРИРОВАННЫХ РАСТВОРАХ И АССОЦИАТАХ
}

Исследование концентрационных эффектов в растворах люминесцирующих соединений позволяет получать детальные сведени'я о взаимодействиях молекул растворенного вещества. К настоящему времени накоплен большой экспериментальный материал по разнообразным проявлениям межмолекулярных взаимодействий в концентрированных растворах пигментов. Однако проблема концентрационного тушения люминесценции сложных органических молекул еще далека от полного разрешения. Существующие теории этого явления (наличие сферы мгновенного тушения по Вавилову $\left[{ }^{1}\right]$, ассоциационная теория $\left[^{2-4}\right]$, предположение о квантовых потерях в актах переноса энергии между молекулами $\left.\left[{ }^{5-7}\right]\right)$ нельзя признать законченными и достаточно общими.

В условиях высоких концентраций сложных молекул в растворе $\left(C \geqslant 10^{-2}\right.$ моль/ $)$, когда межмолекулярные расстояния становятся сравнимыми с размерами молекул люминофора, можно ожидать значительного увеличения энергии взаимодействия молекул и, как следствие, изменения вероятностей внутримолекулярных переходов. В этой связи становятся необходимыми параллельные исследования концентрационного тушения флуоресценции и образования триплетных состояний. B $\left[{ }^{8,9}\right]$ был обнаружен параллелизм в ходе тушения флуоресценции и триплетов для хлорофилла $b$ в лецитине $\left(C=10^{-5}-10^{-2}\right.$ моль/ $\left.\Omega\right)$ при постоянном времени жизни триплетов. В $\left[{ }^{10}\right]$ отмечалось, что для ряда ароматических соединений концентрационное тушение флуоресценции до $C=10^{-1}$ моль/л не сопровождается образованием значительного количества триплетных молекул. Между тем в [ $\left.{ }^{11,12}\right]$ обнаружено расхождение в ходе кривых тушения флуоресценции и триплетов для пирена в этаноле и гексане при $20^{\circ} \mathrm{C}$, исследованного до концентрации $5 \cdot 10^{-2}$ моль/л.

Вывод о неизменности вероятностей внутримолекулярных переходов для хлорофиллоподобных молекул нельзя обобщать на самую интересную, и неисследованную область концентраций $10^{-2}-10^{-1}$ моль/л, где среднее расстояние между молекулами изменяется от 34 до $15 \AA$ и взаимодействие молекул уже может существенно влиять на энергетику внутримолекулярных переходов.

Нами были измерены относительные квантовые выходы флуоресценции и триплетных состояний в широкой области концентраций для хлорофилла $a$, феофитина $a, \mathrm{Al}-\mathrm{Cl}$-фталоцианина и $\mathrm{Na-флуоресцеина}$ $\left[{ }^{13-16}\right]$. Из рисунка видно, что во всех случаях кривые концентрационного тушения выхода триплетов падают менее круто, чем кривые тушения флуоресценции. Расхождение кривых особенно велико для $\mathrm{Na-флуоресценна,} \mathrm{для} \mathrm{которого} \mathrm{выход} \mathrm{триплетов} \mathrm{весьма} \mathrm{слабо} \mathrm{умень-}$ шается с ростом концентрации при резком падении флуоресценции. Отметим незначительное сокращение времени жизни триплетных состояний люминофоров в области $C>10^{-2}$ моль/л. В таблице представлены 

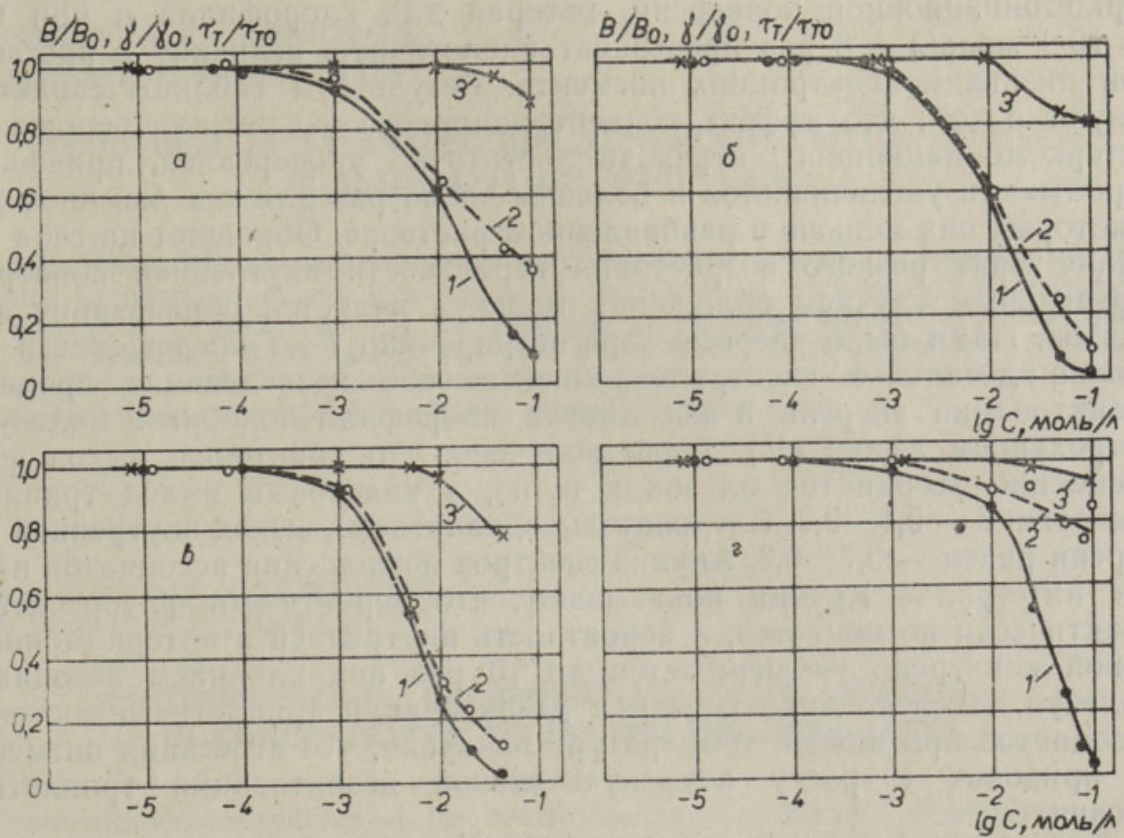

Концентрационные зависимости относительных квантовых выходов флуоресценции (1), образования триплетных состояний (2) и времени жизни триплетного состояния (3) феофитина $a$ в касторовом масле $(a)$, хлорофилла $a$ в касторовом масле (б), Al-Cl-фталоцианина в диметилформамиде (в) и $\mathrm{Na}$-флуоресцеина в глицерине (2).

$B, \gamma \rightarrow t=-90(a, \sigma),-196\left(\right.$ (в) и $-80^{\circ} \mathrm{C}($ ( $) ; \tau_{T} \rightarrow t=-196^{\circ} \mathrm{C}(a-2)$.

Квантовые выходы флуоресценции $(B)$, интеркомбинационной конверсии $(\gamma)$ и вероятности внутримолекулярных переходов в зависимости от концентрации молекул в растворе

\begin{tabular}{|c|c|c|c|c|c|c|c|c|c|}
\hline 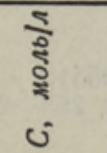 & $B$ & $\gamma$ & $\begin{array}{l}\bar{i} \\
\vdots \\
\vdots \\
\vdots\end{array}$ & $\begin{array}{l}\overline{1} \\
0 \\
i \\
0 \\
0 \\
\dot{i}\end{array}$ & $\begin{array}{c}5 \\
5 \\
\vdots \\
\vdots \\
ن\end{array}$ & $B$ & $\boldsymbol{\gamma}$ & $\begin{array}{l}\overline{1} \\
\vdots \\
\vdots \\
0 \\
\vdots \\
\vdots\end{array}$ & $\begin{array}{l}\bar{t} \\
\vdots \\
\vdots \\
0 \\
0\end{array}$ \\
\hline \multicolumn{5}{|c|}{ Феофи тин $a, f=2,9 \cdot 10^{7} c^{-1}$} & \multicolumn{5}{|c|}{ Хлорофилл $a, f=5,1 \cdot 10^{7} c^{-1}$} \\
\hline $\begin{array}{l}1 \cdot 10^{-4} \\
1 \cdot 10^{-3} \\
1 \cdot 10^{-2} \\
5 \cdot 10^{-2} \\
1 \cdot 10^{-1}\end{array}$ & $\begin{array}{l}0,21 \\
0,20 \\
0,12 \\
0,03 \\
0,02\end{array}$ & $\begin{array}{l}0,79 \\
0,76 \\
0,50 \\
0,34 \\
0,29\end{array}$ & $\begin{array}{l}11,0 \\
11,3 \\
11,7 \\
32,2 \\
44,0\end{array}$ & $\begin{array}{r}\leqslant 0,1 \\
0,7 \\
8,8 \\
58,5 \\
105,8\end{array}$ & $\begin{array}{l}1 \cdot 10^{-4} \\
1 \cdot 10^{-3} \\
1 \cdot 10^{-2} \\
5 \cdot 10^{-2} \\
1 \cdot 10^{-1}\end{array}$ & $\begin{array}{l}0,35 \\
0,32 \\
0,21 \\
0,02 \\
0,002\end{array}$ & $\begin{array}{l}0,65 \\
0,65 \\
0,38 \\
0,16 \\
0,03\end{array}$ & $\begin{array}{r}9,6 \\
10,2 \\
9,3 \\
44,2 \\
79,0\end{array}$ & $\begin{array}{r}\leqslant 0,1 \\
0,4 \\
10,3 \\
234,0 \\
2466,0\end{array}$ \\
\hline \multicolumn{5}{|c|}{$\mathrm{Al}-\mathrm{Cl}-\phi$ т а лоц и ан и н, $f=6 \cdot 10^{7} c^{-1}$} & \multicolumn{5}{|c|}{ 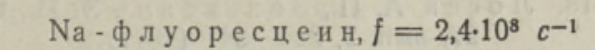 } \\
\hline $\begin{array}{l}1 \cdot 10^{-4} \\
1 \cdot 10^{-3} \\
5 \cdot 10^{-3} \\
1 \cdot 10^{-2} \\
2 \cdot 10^{-2} \\
4 \cdot 10^{-2}\end{array}$ & $\begin{array}{l}0,51 \\
0,46 \\
0,26 \\
0,12 \\
0,05 \\
0,007\end{array}$ & $\begin{array}{l}0,50 \\
0,46 \\
0,26 \\
0,15 \\
0,11 \\
0,05\end{array}$ & $\begin{array}{r}5,9 \\
5,9 \\
5,9 \\
6,8 \\
13,1 \\
42,5\end{array}$ & $\begin{array}{r}\leqslant 0,1 \\
1,2 \\
10,8 \\
22,0 \\
104,0 \\
801,6\end{array}$ & $\begin{array}{r}1 \cdot 10^{-4} \\
1 \cdot 10^{-3} \\
1 \cdot 10^{-2} \\
5 \cdot 10^{-2} \\
7,5 \cdot 10^{-2} \\
1 \cdot 10^{-1}\end{array}$ & $\begin{array}{l}0,97 \\
0,97 \\
0,88 \\
0,22 \\
0,05 \\
0,02\end{array}$ & $\begin{array}{l}0,008 \\
0,008 \\
0,008 \\
0,006 \\
0,005 \\
0,007\end{array}$ & $\begin{array}{l}0,19 \\
0,19 \\
0,19 \\
0,64 \\
2,50 \\
6,90\end{array}$ & $\begin{array}{r}0,55 \\
0,55 \\
3,1 \\
85,1 \\
448,0 \\
977,0\end{array}$ \\
\hline
\end{tabular}

результаты расчетов квантовых выходов и вероятностей внутримолекулярных переходов в зависимости от концентрации исследованных люминофоров. Анализ возможных причин, приводящих к расхождению кривых тушения флуоресценции и триплетов при $C>10^{-2}$ моль/, привел нас к выводу, что это явление связано с возрастанием вероятности ин- 
теркомбинационной конверсии, которая для хлорофилла $a$ при $C=$ $=10^{-1}$ моль/л в 8 раз превышает аналогичную величину в растворах при низких концентрациях пигмента. Результаты таблицы свидетельствуют о том, что эффект концентрационного увеличения вероятности интеркомбинационного перехода достаточно универсален, причем эта вероятность увеличивается в бо́льшее число раз для тех люминофоров, у которых она меньше в разбавленном растворе. Обращает на себя внимание факт резкого возрастания вероятности внутренней конверсии. Предельным случаем сближения молекул является образование ассоциатов. Нами было впервые зарегистрировано $T-T$-поглощение и проведено детальное спектрально-кинетическое исследование процессов дезактивации энергии в ассоциатах хлорофиллоподобных молекул в петролейном эфире $\left[{ }^{17}\right]$. Было получено, что квантовый выход флуоресценции ассоциатов близок к нулю, а квантовый выход триплетов составляет $\sim 0,1-0,3$. Следовательно, квантовый выход внутренней конверсии равен $\sim 0,7-0,9$. Анализ спектров поглощения ассоциатов и расчет интегралов Кравца показывают, что вероятность флуоресценции практически не меняется, а вероятность внутренней и интеркомбинационной конверсии увеличивается до 10 раз под влиянием ассоциации молекул. Исследование кинетики дезактивации триплетного состояния ассоциатов при низкой температуре показало, что агрегация пигментов не приводит к росту безызлучательной дезактивации триплетного уровня.

Таким образом, в концентрированных растворах и ассоциатах хлорофиллоподобных молекул дезактивация энергии электронного возбуждения осуществляется в основном путем внутренней и интеркомбинаци онной конверсии, при этом с ростом концентрации пигментов вероятность обоих процессов существенно возрастает.

\section{Л И Т Е Р А Т У Р А}

1. В а в и л о в С. И., Собрание сочинений, т. 2, М., изд-во АН СССР, 1952.

2. Förster, Th., Fluoreszenz organischer Verbindungen, Vandenhoeck und Ruprecht, Göttingen, 1951.

3. Л ё вшин В. Л., Ж. физ. химии, 6, 1 (1935).

4. Л ё в ш и н В. Л., Изв. АН СССР, сер. физ., 29, 1260 (1965).

5. Г ал анин М. Д., Ж. эксперим. и теор. физ., 28, вып. 4, 485-495 (1955).

6. B о j a rski, C., Ku s b a, J., O b e rmulle r, G., Z. Naturforsch., 26, № 2, 255-259 (1971).

7. Bojarski, C., Bujko, A., Bujko, R., Twardowski, R., Acta Phys. Chem. (Szeged), 23, № 1, 93-99 (1977).

8. Porter, G., Strauss, G., Proc. Roy. Soc., A295, 1-12 (1966).

9. Kelly, A. R., Porter, G., Proc. Roy. Soc., A315, 149-161 (1970).

10. Тибилов С. С., Вемберг Т. М., ЕрмолаевВ. Л., Черкасов А. С., Оптика и спектроскопия, 39, вып. 4, 646-651 (1975).

11. Med inger, T., Wilk in s o n, F., Trans. Farad. Soc., 62, 1785-1792 (1966).

12. Heinzelman, W., Labhart, H., Chem. Phys. Lett., 4, № 1, 20-25 (1969).

13. Л осе в А. П., З ен ькев ич Э. И., С аг ун Е. И., Ж. прикладной спектроскопии, 27, вып. 2, 244-247 (1977).

14. Зенькевич Э. И., Сагун Е. И., Лосев А. П., Гуринович Г. П., Ж. прикладной спектроскопии, 32, вып. 6, 1047-1055 (1980).

15. Лосев А. П., З ен вевич Э. И., Сагун Е. И., Изв. АН СССР, сер. физ., 44, № 4, 783-788 (1980).

16. Зен ькевич Э. И., С агун Е. И., Лосев А. П., Гуринович Г. П., Оптика и спектроскопия, 49, вып. 5, 896-902 (1980).

17. Гу у и нови ч Г. П., Л осе в А. П., С а гун Е. И., Ж. прикладной спектроскопии, 26, № 6, 1028-1034 (1977).

Институт физики

Академии наук Белорусской ССР 
E. I. SAGUN, G. P. GURINOVITS,

A. P. LOSSEV, E. I. ZENKEVITS

\title{
KLOROFOLLI JA TA ANALOOGIDE KONTSENTREERITUD LAHUSTE JA ASSOTSIAATIDE FOTOFUOSIKA
}

On uuritud klorofüllisarnaste molekulide kontsentreeritud lahuste ja assotsiaatide fluorestsentsi ja interkonversiooni kvantsaagiseid. On tōestatud, et kõrgete kontsentratsioonide piirkonnas $\left(C \geqslant 10^{-2} \mathrm{mool} / \mathrm{l}\right)$ fluorestsentsi kvantsaagise kõverad muutuvad järsemalt kui interkonversiooni omad. Tulemust on seletatud interkonversiooni tõenäosuse kasvuga. On avastatud seesmise konversiooni ja interkonversiooni järsk kasv üleminekul assotsiaatidele, ning arutletud nähtuse võimalike põhjuste üle.

\author{
E. I. SAGUN, G. P. GURINOVICH, \\ A. P. LOSEV, E. I. ZEN'KEVICH
}

\section{PHOTOPHYSICS OF CHLOROPHYLL AND ITS ANALOGUES IN CONCENTRATED SOLUTIONS AND ASSOCIATES}

The concentration dependence of the relative quantum yields of luminescence and an intersystem crossing into a triplet state of pigments and dyes have been studied in the solutions and chlorophyll aggregates. A growth of the intersystem crossing probability is observed. This can be explained by the interaction between molecules at their approach. The nossible reasons of the growth of the internal conversion probability under the rise of concentration or at the association of molecules are discussed. 